\title{
BMJ Serum perfluoroalkyl acids Open concentrations and memory impairment in a large cross-sectional study
}

\author{
Valentina Gallo, ${ }^{1,2}$ Giovanni Leonardi, ${ }^{1}$ Carol Brayne, ${ }^{3}$ Ben Armstrong, ${ }^{1}$ \\ Tony Fletcher ${ }^{1}$
}

To cite: Gallo V, Leonardi $\mathrm{G}$ Brayne C, et al. Serum perfluoroalkyl acids concentrations and memory impairment in a large crosssectional study. BMJ Open 2013:3:e002414.

doi:10.1136/bmjopen-2012002414

- Prepublication history and additional material for this paper is available online. To view these files please visit the journal online (http://dx.doi.org/10.1136/ bmjopen-2012-002414).

Received 27 November 2012 Revised 30 April 2013 Accepted 30 April 2013

This final article is available for use under the terms of the Creative Commons Attribution Non-Commercial 2.0 Licence; see http://bmjopen.bmj.com

\footnotetext{
${ }^{1}$ Department of Social and Environmental Health Research, London School of Hygiene and Tropical Medicine, London, UK ${ }^{2}$ Centre for Primary Care and Public Health, Blizard Institute, Queen Mary, University of London, London, UK

${ }^{3}$ Department of Public Health and Primary Care, University of Cambridge, Cambridge, UK
}

\section{Correspondence to} Dr Valentina Gallo; v.gallo@qmul.ac.uk

\begin{abstract}
Objectives: To examine the cross-sectional association between serum perfluorooctanate (PFOA), perfuorooctane sulfonate (PFOS), perfluorononanoic acid (PFNA) and perfluorohexane sulfonate (PFHxS) concentrations with self-reported memory impairment in adults and the interaction of these associations with diabetes status.
\end{abstract}

Design: Cross-sectional study.

Setting: Population-based in Mid-Ohio Valley, West Virginia following contamination by a chemical plant.

Participants: The C8 Health Project collected data and measured the serum level of perfluoroalkyl acids (PFAAs) of 21024 adults aged 50+ years.

Primary outcome measure: Self-reported memory impairment as defined by the question 'have experienced short-term memory loss?'

Results: A total of 4057 participants self-reported short-term memory impairment. Inverse associations between PFOS and PFOA and memory impairment were highly statistically significant with fully adjusted OR $=0.93(95 \% \mathrm{Cl} 0.90$ to 0.96$)$ for doubling PFOS and $\mathrm{OR}=0.96(95 \% \mathrm{Cl} 0.94$ to 0.98$)$ for doubling PFOA concentrations. Comparable inverse associations with PFNA and PFHxS were of borderline statistical significance. Inverse associations of PFAAs with memory impairment were weaker or non-existent in patients with diabetes than overall in patients without diabetes.

Conclusions: An inverse association between PFAA serum levels and self-reported memory impairment has been observed in this large population-based, crosssectional study that is stronger and more statistically significant for PFOA and PFOS. The associations can be potentially explained by a preventive antiinflammatory effect exerted by a peroxisome proliferator-activated receptor agonist effect of these PFAAs, but confounding or even reverse causation cannot be excluded as an alternative explanation.

\section{INTRODUCTION}

Perfluoroalkyl acids (PFAAs) are man-made compounds used during the manufacture of fluoropolymers including non-stick cookware

\section{ARTICLE SUMMARY}

Article focus

- Cross-sectional association between the serum level of perfluorooctanate (PFOA), perfluoro-octane sulfonate (PFOS), perfluorononanoic acid (PFNA) and perfluorohexane sulfonate (PFHxS) and selfreported memory impairment in a population exposed to high levels of PFOA.

- Potential interaction between the association of perfluoroalkyl acids (PFAAs) with memory impairment by diabetes status.

\section{Key messages}

- Inverse associations between PFOS and PFOA and memory impairment were statistically significant, perhaps due to a potential antiinflammatory effect exerted through a peroxisome proliferator-activated receptor agonism. Comparable inverse associations with PFNA and PFHxS were of borderline statistical significance.

- Inverse associations of PFAAs with memory impairment were weaker or non-existent in patients with diabetes than overall in patients without diabetes. Analysis further stratified by specific diabetes medication use showed no variation in ORs more than explicable by chance given the number of tests made.

Strengths and limitations of this study

- Very large sample size including 21024 adults with a measured serum level of PFAAs with a given geographical distribution allowing some multilevel modelling.

- The cross-sectional nature of the design does not allow any causal inference and makes results particularly prone to reverse causality.

- A self-report is not an optimal method for estimating the degree of memory impairment in a population.

and breathable, yet waterproof, fabrics. They can also result from the metabolism of fluorinated telomers, compounds used for food package coatings, carpet treatments and stain-resistant fabric treatment. Perfluorooctanate (PFOA), perfuorooctane 
sulfonate (PFOS), perfluorononanoic acid (PFNA) and perfluorohexane sulfonate (PFHxS) persist in the environment and are found in the blood of humans and many animal species throughout the world. ${ }^{1}{ }^{2}$ Potential sources of exposure to PFAAs in humans include drinking water, dust, breast milk, fish and other foods, food packaging, ambient air, and occupational exposure. ${ }^{3-6}$

In animal models, perfluoroalkyl chemicals can activate peroxisome proliferator-activated receptor $\alpha$ $($ PPAR $\alpha)$, a ligand-activated transcription factor that regulates gene expression, lipid modulation, glucose homeostasis, cell proliferation and inflammation. ${ }^{78}$ The PPAR receptor has been involved in the ageing process: PPAR $\alpha$ null mice showed decreased longevity compared with wild-type mice due to non-neoplastic spontaneous ageing lesions which occurred with a higher incidence and a shorter latency in the PPAR $\alpha$ null mice. ${ }^{9}$ Also, $\operatorname{PPAR} \gamma$ variants were reported to be associated with longevity in humans with low-insulin resistance. ${ }^{10}{ }^{11}$ Activation of the PPAR $\gamma$ receptor in vitro and in vivo also prevents the expression of inflammatory cytokines and other inflammatory mediators in brains of Alzheimer's disease animal models. ${ }^{12}{ }^{13}$ In addition, PPAR $\gamma$ agonists have been demonstrated to suppress the A $\beta$-mediated activation of microglia in vitro and prevent cortical or hippocampal neuronal cell death. ${ }^{14-16}$ PPAR $\gamma$ is also deeply involved in diabetes, given its ability to orchestrate the expression of genes involved in lipid metabolism, adipogenesis and inflammation. It is activated by endogenous ligands (such as fatty acids and prostaglandins) or drugs such as thiazolidinedione. It is most highly expressed in adipocytes where it acts as the master regulator of adipogenesis via induction of adipogenic genes. ${ }^{17}$ However, a study in vitro showed that PFOA and PFOS activate differentially PPAR $\alpha$ and $\operatorname{PPAR} \gamma$ receptors, but it is not possible to directly extrapolate these results to toxicity studies in vivo. ${ }^{18}$ Therefore, in line with what was recently observed by Power $e t a l,{ }^{19}$ we hypothesised that increased exposure to PFAA could be associated with a better cognitive function.

The positive association between diabetes and cognitive impairment is well established ${ }^{20}$; some studies investigating the association between PFOA exposure and diabetes suggested the presence of an inverse association: a negative trend in diabetes occurrence by increasing serum PFOA deciles was found in a casecontrol study nested in a previous study based on the population investigated here, ${ }^{21} 22$ but not in others. ${ }^{23} 24$

From 1950 to 2005, a chemical plant in the Mid-Ohio Valley, West Virginia was responsible for emitting PFOA into the surrounding environment. In 2001, a group of residents from the nearby West Virginia and Ohio communities filed a class action lawsuit alleging health damage from drinking water supplies drawing on PFOA-contaminated groundwater. ${ }^{25}$ Part of the pretrial settlement of the class action lawsuit included a baseline survey, the C8 Health Project, conducted in 2005-2006, that gathered data from over 69000 people from six contaminated water districts surrounding the plant. ${ }^{25} \mathrm{In}$ the present population, PFOA concentrations ranged from US background levels to very high; overall, the PFOA levels are much higher in this population (geometric mean $42.6 \mathrm{ng} / \mathrm{ml}, 95 \%$ CI 41.8 to 43.3 ) than in the corresponding US population surveys (NHANES in same year mean $3.95 \mathrm{ng} / \mathrm{ml}, 95 \%$ CI 3.65 to 4.27$).{ }^{1}{ }^{25}$ The mean PFOS (geometric mean 22.4, 95\% CI 22.2 to 22.6), PFNA (1.37, 95\% CI 1.36 to 1.38 ) and PFHXs (3.18, 95\% CI 3.15 to 3.22$)$ closely resembled values from a nationally representative US sample from a similar time frame (mean PFOS 20.7, 95\% CI 19.2 to 22.3; mean PFNA $0.97,95 \%$ CI 0.82 to 1.14 and PFHXs $1.93,95 \%$ CI 1.73 to 2.16$){ }^{1}$

The present study uses these data to examine the cross-sectional association between serum PFOA, PFOS, PFNA and PFHxS concentrations with self-reported memory impairment in adults, and its potential interaction with diabetes status.

\section{METHODS}

\section{Study population}

This study is one of the C8 Science Panel Studies that uses information from questionnaires and blood tests collected in the C8 Health Project, supplemented by further information on classification by water district developed in a companion C8 Science Panel Study.

The C8 Health Project enrolled eligible participants between August 2005 and August 2006. Individuals were eligible to participate in the C8 Health Project if they had consumed water for at least 1 year between 1950 and 3 December 2004 while living, working or going to school in one of the following six water districts: Little Hocking Water Association of Ohio; City of Belpre, Ohio; Tupper Plains-Chester District of Ohio; Village of Pomeroy, Ohio; Lubeck Public Service District of West Virginia; Mason County Public Service District of West Virginia or private water sources within aforementioned districts and areas of documented PFOA contamination. Details of the study enrolment process, including consenting procedures, have been described elsewhere. ${ }^{25}$

The C8 Health Project collected data on 69030 people. The participation rate for the C8 Health Project, based on US census counts of residents in the affected water districts during Project enrolment, has been estimated at around $80 \% .^{25} \mathrm{In}$ this population, the strongest predictor of PFOA serum concentration was residence in one of the contaminated water districts ${ }^{26}$; the serum levels of other PFAAs do not show such geographic variation. Of the population, 21724 older adults (aged $\geq 50$ years) were considered for this analysis, and a total of $21024(96.8 \%)$ were included in the final analysis after exclusion of participants with missing data on ethnicity, education level, socioeconomic status, cigarette smoking or body mass index (BMI) measurements. 


\section{Memory impairment definition}

During the survey (2005-2006), all participants were asked if they 'had experienced short-term memory loss', the possible answers being 'frequently', 'sometimes', 'rarely' and 'never'. The principle analyses assessed memory impairment defined as reporting short-term memory loss frequently or sometimes, compared with rarely and never. Memory impairment ever was also considered, defined as reporting any memory loss and compared with the never category.

\section{Laboratory analysis}

Blood samples were obtained and processed at individual data collection sites. Samples were drawn into four tubes/participant, with a maximum $35 \mathrm{ml}$. Tubes were spun, aliquoted and refrigerated until shipping. Samples were shipped on dry ice daily from each data collection site to the laboratory daily. ${ }^{25}$ Participants were not asked to fast before blood sample withdrawal, but fasting status was recorded.

Laboratory analysis of PFAAs used an automated solidphase extraction combined with reverse-phase highperformance liquid chromatography. ${ }^{27}$ Analyses were conducted by the Exygen Research Inc, State College, Pennsylvania, USA; an intralaboratory quality assurance programme was carried out by analysis of duplicate samples at AXYS Analytical Service Ltd, Sidney, British Columbia, Canada. ${ }^{25}$ The intralaboratory coefficient of variation for all PFAAs measurements was 0.1 ; the interlaboratory comparison coefficient of variation was 0.2 for PFOA and PFNA, 0.1 for PFOS and not applicable for PFHxA as all in the second lab measurement values were below the level of detection. ${ }^{25}$ The detection limit for all PFAAS was $0.5 \mathrm{ng} / \mathrm{ml}$ and observations below this limit were assigned a value of $0.25 \mathrm{ng} / \mathrm{ml}(\mathrm{n}=16, \mathrm{n}=101$, 532 and 387 for PFOA, PFOS, PFNA and PFHxS, respectively, for this study population). All PFAAs concentration distributions were skewed to the right. Methods and results are reported according to the STROBE-ME recommendations. ${ }^{28}$

\section{Statistical analysis}

Associations between exposure (serum concentrations of PFOA, PFOS, PFNA and PFHxS) and memory impairment were studied using logistic regression. Minimally adjusted models included age, in 1-year age-band, race (white, black and others), gender and educational level (highschool diploma or general educational development, some college, bachelor's degree or higher; model 1). Further adjusted models additionally included average household income $(\leq \$ 10000, \$ 10001-20000, \$ 20001-$ 30 000, \$30 001-40 000, \$40 001-50 000, \$50 001-60 000, $\$ 60$ 001-70 000, >\$70 000), physical activity, alcohol consumption (none, $<1 \mathrm{drink} / \mathrm{month},<1 \mathrm{drink} /$ week, few drinks/week, $>1$ drink/day) and cigarette smoking (never smoker, former smoker, current smoker $<10$ cigarettes/ day, current smoker 10-19 cigarettes/day, current smoker $\geq 20$ cigarettes/day; model 2 ). Fully adjusted models also included BMI (underweight/normal weight; overweight and obese class I, II and III) and diabetes (model 3). PFAA concentrations were log-transformed to reduce skewness. For each model, the association between PFAAs and self-reported memory impairment was calculated for a doubling in PFAA concentration in a model with PFAA entered as a continuous covariate, for quintile groups of the PFAA distribution and by ordinal regression analysis with the outcome variable comprising the four original levels of self-reported frequency of episodes of memory loss, again in relation to a doubling of PFAAs. To explore the possible differential effects of PFAA in subgroups, analyses were further stratified by diabetes status and, among patients with diabetes, by type of medications.

The following four sensitivity analyses were carried out: first, one analysis restricting the sample to 7097 participants aged 65 years and older. Second, an analysis conducted on the entire sample, but using as outcome definition those reporting any memory loss (frequently, sometimes and rarely). Our final sensitivity analysis utilises the geographical clustering of PFOA exposure by water districts which allowed use to decompose the overall estimate of association of PFOA with memory impairment within and between water district components, by including as explanatory variables both water district mean logged PFOA serum concentration and the deviations of individual values from their district mean. ${ }^{29}$ These two associations are subject to different potential biases, thus helping interpretation.

\section{Role of funding}

Funding for this work, the 'C8 Science Panel Community Study at London School of Hygiene and Tropical Medicine-LSHTM', comes from the C8 Class Action Settlement Agreement (Circuit Court of Wood County, West Virginia, USA) between DuPont and the plaintiffs, which resulted from releases of PFOA (or C8) into drinking water. It is one of the C8 Science Panel Studies undertaken by the Court-approved C8 Science Panel established under the same Settlement Agreement. The task of the C8 Science Panel, of which Tony Fletcher is a member, is to undertake research in the Mid-Ohio Valley, and subsequently evaluate the results along with other available information to determine if there are any probable links between PFOA and disease. Funds were administered by the Garden City Group (Melville, New York, USA) that reports to the Court. The authors of this manuscript declare that their ability to design, conduct, interpret or publish research was unimpeded by and fully independent of the court and/or settling parties. In addition, they declare no competing financial interests. The LSHTM Ethics Committee approved this study.

\section{RESULTS}

A total of 4462 participants (21.2\% of the entire population of 21024 individuals aged 50 years or older) self- 


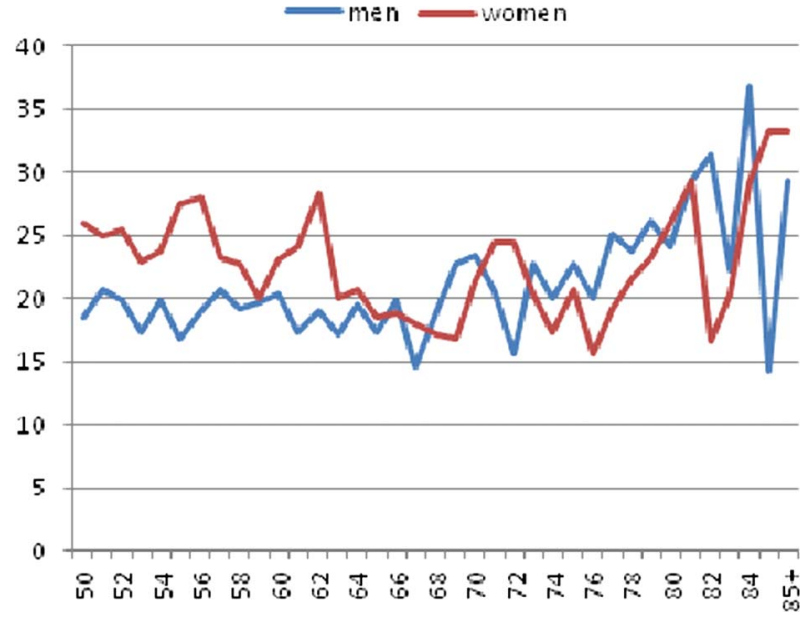

Figure 1 Prevalence of self-reported short-term memory impairment by age and sex in the study population.

reported short-term memory impairment (figure 1): episodes of short-term memory loss were reported frequently by 1115 participants $(5.3 \%)$; sometimes by 3347 (15.9\%); rarely by $4283(20.4 \%)$ and never by 12279 $(58.4 \%)$. Many personal characteristics were associated individually with memory loss, including higher age, lower socioeconomic status, smoking and diagnosis of diabetes (table 1), though to what extent these reflected independent risk factors was not investigated.

Results from the logistic regression of association between PFAAs and memory impairment are shown in table 2. Results for the minimally, further and fully adjusted models were similar, so we show only the further adjusted results in this table, but results for all models are in the online supplementary table S1. Inverse associations between PFOS and PFOA and memory impairment were highly statistically significant with adjusted $\mathrm{OR}=0.93$ (0.90 to 0.96) for PFOS and $\mathrm{OR}=0.96$ (0.94 to 0.98) for PFOA for doubling PFAA concentrations. Inverse associations of similar magnitude with PFNA and PFHxS but of borderline statistical significance were found: OR=0.96 (0.92 to 1.02) for PFNA and $\mathrm{OR}=0.97$ (0.94 to 1.00$)$ for PFHxS. The analysis by the PFAA quintile groups shows similar patterns.

Inverse associations of PFAAs with memory impairment were weaker or non-existent in patients with diabetes than in patients without diabetes (table 3), though ORs were imprecise, and the difference by diabetes status was only significant for PFOA ( $p$ value for interaction $=0.014$ ). Analysis further stratified by specific diabetes medication use showed no variation in ORs more than explicable by chance given the number of tests made (see online supplementary table S2).

In the sensitivity analysis on participants older than 65 years, the substantial reduction of the sample size resulted in loss of precision in ORs. However, the points estimates of associations with memory impairment were of comparable magnitude for all PFAAs except PFOA for which the association with memory impairment was close to null ( $\mathrm{OR}=0.99$ (0.97 to 1.03); table 4).

The analysis carried out on the entire sample, comparing those with any memory impairment against those with no memory problems, shows slightly weaker associations for each of the PFAAs but precision was reduced (table 4). Analyses using ordinal regression in place of binary logistic regression yielded similar results to the logistic regressions (tables 2-4).

The analysis separating the PFOA-memory impairment association within and between water district components found that within water districts there was an inverse association between PFOA and memory impairment, as in the overall association (OR 0.94, 95\% CI 0.91 to 0.98 , scale and adjustments as before). However, there was no association between geometric mean concentration and memory impairment (OR 1.00, 95\% CI 0.97 to 1.03 , per doubling in geometric mean PFOA by district).

\section{DISCUSSION}

An inverse association between PFAAs serum levels (including PFOS, PFOA, PNA and PFHxS) and selfreported memory impairment has been observed in this large population-based, cross-sectional study. This association is more clearly monotonic with increasing exposure, and more statistically significant for PFOA and PFOS. However, the consistent decrement for all PFAAs suggests a common mechanism.

It is plausible that PFAAs could have an effect on cognitive function via PPAR agonism. Although it is not clear to what extent PFAAs act differentially on the PPAR receptors $\alpha$ and $\gamma,{ }^{18}$ it could be speculated that this association might be mediated by the activation of the PPAR receptor by PFAAs. Activation of the PPAR $\gamma$ receptors has been shown to decrease the secretion of proinflamatory cytokines and possibly increase phagocytosis of $A \beta$ inclusions, probably through the activation of microglia. ${ }^{30}$ However, there was a suggestion that this effect of suppression of the activation of microglia was age-dependent or disease stage-dependent, being not significant in patients with advanced Alzheimer's disease. ${ }^{31}{ }^{32}$ PPAR agonist drugs, such as non-steroidal anti-inflammatory drugs and some antidiabetic drugs (ie, thiazolidinedione or pioglitazone), have been proposed as preventive drugs for neurodegenerative conditions, including Alzheimer's dementia. ${ }^{30} 33$

In a previous published study, an inverse association between PFAAs and memory impairment was observed specifically among non-medicated patients with diabetes. ${ }^{19}$ In the present study, this pattern was not replicated, with the inverse association between PFAAs and cognitive impairment being more evident in those without diabetes; among patients with diabetes, the association was not present, irrespective of treatment status. This finding could be explained by the fact that in patients with diabetes, PPAR receptors are more 
Table 1 Participant characteristics, Mid-Ohio Valley, 2005-2006 ( $\mathrm{N}=21024)$

\begin{tabular}{|c|c|c|}
\hline & All $\mathrm{N}=21024^{*}$ & Memory impaired $\mathrm{N}=4462 \dagger$ \\
\hline Males, n (\%) & $10353(49.2)$ & $2040(19.7)$ \\
\hline Females, n (\%) & $10671(50.8)$ & $2422(22.7)$ \\
\hline Age, median/mean (SD) & $60.5 / 62.3(9.0)$ & $59.9 / 62.3(9.4)$ \\
\hline \multicolumn{3}{|l|}{ Age groups (year) } \\
\hline $50-54$ & $5381(25.6)$ & $1185(22.0)$ \\
\hline $55-59$ & $4831(23.0)$ & $1055(21.8)$ \\
\hline $60-64$ & $3715(17.7)$ & 740 (19.9) \\
\hline $65-69$ & 2930 (13.9) & $535(18.3)$ \\
\hline $70-74$ & $1979(9.4)$ & 419 (21.2) \\
\hline $75-79$ & $1251(6.0)$ & $269(21.5)$ \\
\hline $80+$ years & $937(4.5)$ & $259(27.6)$ \\
\hline Regular exercise, n (\%) & $6774(32.2)$ & 1306 (19.3) \\
\hline \multicolumn{3}{|l|}{ BMI, n (\%) } \\
\hline Normal weight & $5100(24.3)$ & $1051(20.6)$ \\
\hline Overweight & 8194 (39.0) & $1612(19.7)$ \\
\hline Obese class I & $4789(22.8)$ & $1028(21.5)$ \\
\hline Obese class II & $1805(8.6)$ & 457 (25.3) \\
\hline Obese class III & $1136(5.4)$ & $314(27.6)$ \\
\hline \multicolumn{3}{|l|}{ Household income, \$/year n (\%) } \\
\hline$\leq 10000$ & $1486(7.1)$ & $448(30.2)$ \\
\hline $10001-20000$ & 3059 (14.6) & 757 (24.8) \\
\hline $20001-30000$ & $3281(15.6)$ & 751 (22.9) \\
\hline $30001-40000$ & $2936(14.0)$ & $572(19.5)$ \\
\hline $40001-50000$ & $2135(10.2)$ & $422(19.8)$ \\
\hline $50001-60000$ & $1815(8.6)$ & $359(19.8)$ \\
\hline $60001-70000$ & $1367(6.5)$ & $268(19.6)$ \\
\hline$>70000$ & $2882(13.7)$ & $480(16.7)$ \\
\hline Undetermined & $2063(9.8)$ & 405 (19.6) \\
\hline \multicolumn{3}{|l|}{ Education, n (\%) } \\
\hline$<12$ years & $3310(15.7)$ & $845(25.5)$ \\
\hline HS diploma or GED & 9704 (46.2) & 1979 (20.4) \\
\hline Some college & $5612(26.7)$ & $1204(21.5)$ \\
\hline Bachelor degree or higher & $2398(11.4)$ & $434(18.1)$ \\
\hline \multicolumn{3}{|l|}{ Race, $\mathrm{n}(\%)$} \\
\hline White & $20514(97.6)$ & 4349 (21.2) \\
\hline Black & $213(1.0)$ & 38 (17.8) \\
\hline Other & $297(1.4)$ & $75(25.3)$ \\
\hline \multicolumn{3}{|l|}{ Alcohol consumption, $\mathrm{n}(\%)$} \\
\hline None & $13276(63.2)$ & $2848(21.5)$ \\
\hline$<1$ drink/month & 2589 (12.3) & $597(23.1)$ \\
\hline$<1$ drink/week & $1530(7.3)$ & $309(20.2)$ \\
\hline Few drinks/week & 2087 (9.9) & $397(19.0)$ \\
\hline 1-3 drinks/day & 805 (3.8) & $142(17.6)$ \\
\hline >3 drinks/day & $310(1.5)$ & $66(21.3)$ \\
\hline Undetermined & $427(2.0)$ & $103(24.1)$ \\
\hline \multicolumn{3}{|l|}{ Smoking status, n (\%) } \\
\hline Never smoker & $9804(46.6)$ & $1906(19.4)$ \\
\hline Former smoker & $7555(35.8)$ & $1693(22.5)$ \\
\hline Current smoker $<10$ cigarette/day & $1212(5.8)$ & $256(21.1)$ \\
\hline Current smoker $10-19$ cigarette/day & $1260(6.0)$ & $310(24.6)$ \\
\hline Current smoker $20+$ cigarette/day & $1213(5.8)$ & $297(24.5)$ \\
\hline Diabetes, n (\%) & $3443(16.4)$ & $875(25.4)$ \\
\hline Thiazolidinedion use $\sim$ & 809 (23.5) & $202(25.0)$ \\
\hline Other medications & $1244(36.1)$ & $321(25.8)$ \\
\hline No medication & $1390(40.4)$ & $352(25.3)$ \\
\hline
\end{tabular}

${ }^{*}$ Percentages refer to the proportion with respect to the entire population.

†Percentages reflect the proportion of memory impaired in each category; percentages among patients with diabetes only. BMI, body mass index; GED, general educational development. 
Table 2 Association between PFAAs and self-report memory impairment in logistic regression for a doubling PFAA concentration, by quintiles of PFAAs and in ordinal regression $(n=21024)$

\begin{tabular}{|c|c|c|}
\hline & $\begin{array}{l}\text { Range } \\
\text { (ng/ml) }\end{array}$ & $\begin{array}{l}\text { Adjusted OR and } \\
95 \% \mathrm{Cl}^{*}\end{array}$ \\
\hline PFOS & & 0.93 (0.90 to 0.96$)$ \\
\hline 1st quintile & $0.25-14.4$ & Ref. \\
\hline 2nd quintile & $14.5-20.4$ & $0.96(0.87$ to 1.07$)$ \\
\hline 3rd quintile & $20.5-27.1$ & 0.86 (0.78 to 0.96$)$ \\
\hline 4th quintile & $27.2-37.2$ & 0.87 (0.78 to 0.96$)$ \\
\hline 5th quintile & $37.3-759.2$ & $0.85(0.76$ to 0.94$)$ \\
\hline Trend & & $<0.001$ \\
\hline Ordinal regression & & 0.95 (0.93 to 0.98$)$ \\
\hline PFOA & & $0.96(0.94$ to 0.98$)$ \\
\hline 1st quintile & $0.25-14.0$ & Ref. \\
\hline 2nd quintile & $14.1-27.0$ & $0.88(0.79$ to 0.97$)$ \\
\hline 3rd quintile & $27.1-53.8$ & 0.83 (0.75 to 0.92$)$ \\
\hline 4th quintile & $53.9-118.1$ & $0.79(0.71$ to 0.88$)$ \\
\hline 5th quintile & 118.3-22412 & $0.79(0.71-0.88)$ \\
\hline Trend & & $<0.001$ \\
\hline Ordinal regression & & 0.97 (0.96 to 0.98$)$ \\
\hline PFNA & & $0.96(0.91$ to 1.00$)$ \\
\hline 1st quintile & $0.25-0.90$ & Ref. \\
\hline 2nd quintile & $1.0-1.2$ & 0.86 (0.78 to 0.96$)$ \\
\hline 3rd quintile & $1.3-1.4$ & 0.87 (0.77 to 0.98$)$ \\
\hline 4th quintile & $1.5-1.9$ & $0.86(0.77$ to 0.95$)$ \\
\hline 5th quintile & $2.0-28.6$ & 0.89 (0.80 to 0.99$)$ \\
\hline Trend & & 0.053 \\
\hline Ordinal regression & & $0.97(0.94-1.01)$ \\
\hline $\mathrm{PFH} \times \mathrm{S}$ & & $0.96(0.93-0.99)$ \\
\hline 1st quintile & $0.25-1.7$ & Ref. \\
\hline 2nd quintile & $1.8-2.6$ & $1.01(0.91-1.12)$ \\
\hline 3rd quintile & $2.7-3.6$ & $1.02(0.91-1.13)$ \\
\hline 4th quintile & $3.7-5.6$ & $0.93(0.84-1.04)$ \\
\hline 5th quintile & $5.7-232.6$ & $0.89(0.79-0.99)$ \\
\hline Trend & & 0.009 \\
\hline Ordinal regression & & $0.97(0.94-0.99)$ \\
\hline
\end{tabular}

*Model adjusted for age (1-year age bands), ethnicity, gender and school level (categorical), household income (categorical), physical activity, alcohol consumption (categorical, none/ $<1$ drink/ month, $<1$ drink/week, few drinks/week, 1-3 drinks/day, >3 drinks/ day, undetermined) and cigarette smoking (categorical, never, former, <10 cigarette/day, 12-20 cigarette/day, 20+ cigarette/day). PFAA, perfluoroalkyl acids; PFHxS, perfluorohexane sulfonate; PFNA, perfluorononanoic acid; PFOA, perfluorooctanate; PFOS, perfuorooctane sulfonate.

phosphorylated with a consequent reduced transcriptional activity, ${ }^{34}{ }^{35}$ and the balance between PPAR $\gamma$ expression and activity levels is altered. ${ }^{34}{ }^{36}$ It is therefore possible-based on the present data-that the PPAR-agonist effect of PFAAs is different in participants with and without PPAR-mediated metabolic changes such as diabetes. Also, it has been reported that PFAAs have a PPAR agonist effect, more prominently PPAR- $\alpha^{37}$; animal models suggest that PFOA has a stronger agonistic effect than PFOS. ${ }^{37}$ Our findings of an inverse association between PFAA and memory impairment among patients without diabetes would therefore be compatible with a possible anti-inflammatory role exerted by PFAA on early symptoms of cognitive impairment.

There is some evidence of detrimental effects of PFAAs in the neurodevelopment of mice affecting the cholinergic system and cognitive function ${ }^{38-40}$; thus, the timing of exposure may also be relevant in order for the PFAAs to exert this hypothesised antidementing role. However, these findings should be interpreted cautiously, given the limitations of the study. First, given the cross-sectional nature of the study, reverse causality must be considered: participants suffering from memory impairment could have consumed less of these compounds via water and food sources, though this is not a likely explanation, given the consistency of the association across various PFAAs which have substantially different routes of exposure. Host characteristics such as genotype could be correlated with both some mechanism predisposing these symptoms and variation in the PFAA excretion rates, thus leading to a confounded association with the serum levels. Further, a self-report is not a very accurate method for ascertaining memory impairment, although errors in classification would be expected to be non-differential misclassification, biasing the estimate of association towards the null. The effects of PFAA have been mostly studied in relation to PPAR $\alpha,{ }^{7}$ while the receptor is mostly implicated in metabolic changes and diabetes and in dementia PPAR $\gamma^{30}$; however, these two belong to the same receptor family and some degree of cross-activation cannot be excluded, and the knowledge of their pleiotropic effects is currently advancing. ${ }^{41}$ Lastly, the classification into different antidiabetic medications is uncertain as these were selfreported and not prompted by interviewers. However, we consider it very unlikely that any misreporting would be confounded with serum PFAAs. This would tend to low specificity and thus bias of the association (if any) towards the null.

On the other hand, the strengths of this study include the fact that all the estimates shown were adjusted for numerous potential confounders, including age in 1-year age bands, making the effect of PFAA on memory impairment not likely to be confounded by lifestyle characteristics. Furthermore, these results are based on a very large population representative of the general population in West Virginia and $\mathrm{Ohio}^{25}$; thus, the estimates are solid; and the $21 \%$ prevalence of memory impairment is compatible and consistent with the figures on the prevalence of dementia reported for North America. ${ }^{42}$

Individual serum levels reflect the contributions of both the intake and retention/excretion rates. While we have no direct data on either of these components, the large differences in drinking water contamination and associated average population serum levels for PFOA in the six water districts allow an estimate of the effect of exposure. That the association with PFOA was entirely within the water districts, and not present at all between water districts despite the large differences in 
Table 3 Association between PFAAs and self-report memory impairment in logistic regression for a doubling PFAA concentration, by quintiles of distribution and in ordinal regression by diabetes status (validated by clinical records)

\begin{tabular}{|c|c|c|c|c|c|c|}
\hline & $\begin{array}{l}\text { Range } \\
\text { (ng/ml) } \\
\text { PFOS } \\
\text { N=17832 }\end{array}$ & OR $(95 \% \mathrm{Cl})^{\star}$ & $\begin{array}{l}\text { p Value } \\
\text { for inter }\end{array}$ & $\begin{array}{l}\mathrm{N} \\
\text { PFOA } \\
\mathrm{N}=17832\end{array}$ & OR $(95 \% \mathrm{Cl})^{*}$ & $\begin{array}{l}\text { p Value } \\
\text { for inter }\end{array}$ \\
\hline $\begin{array}{l}\text { Patients without } \\
\text { diabetes }\end{array}$ & & $0.93(0.90$ to 0.96$) \dagger$ & - & & $0.95(0.93$ to 0.97$) \dagger$ & - \\
\hline Ordinal regression & & $0.96(0.93$ to 0.99$)$ & & & $0.96(0.95$ to 0.98$)$ & \\
\hline 1st quintile & $0.25-14.5$ & Ref. & & $0.25-14.3$ & Ref. & \\
\hline 2nd quintile & $14.6-20.5$ & 0.96 (0.86 to 1.08$)$ & & $14.4-27.2$ & 0.85 (0.76 to 0.95$)$ & \\
\hline 3rd quintile & $20.6-27.0$ & $0.90(0.80$ to 1.01$)$ & & $27.3-54.3$ & $0.82(0.73$ to 0.92$)$ & \\
\hline 4th quintile & $27.1-37.1$ & $0.88(0.78$ to 0.99$)$ & & $54.4-119.1$ & $0.76(0.68$ to 0.86$)$ & \\
\hline 5th quintile & $37.2-759.2$ & $0.85(0.76$ to 0.96$)$ & & $119.2-8416$ & $0.75(0.67$ to 0.84$)$ & \\
\hline \multirow[t]{2}{*}{ Trend } & & 0.002 & & & $<0.001$ & \\
\hline & $\mathrm{N}=3192$ & & & $\mathrm{~N}=3192$ & & \\
\hline $\begin{array}{l}\text { Patients with } \\
\text { diabetes }\end{array}$ & & $0.94(0.88$ to 1.02$) \dagger$ & 0.698 & & $1.02(0.97$ to 1.06$) \dagger$ & 0.014 \\
\hline Ordinal regression & & $0.95(0.90$ to 1.01$)$ & & & $1.00(0.97$ to 1.04$)$ & \\
\hline 1st quintile & $0.25-13.6$ & Ref. & & $0.25-12.6$ & Ref. & \\
\hline 2nd quintile & $13.7-20.0$ & $1.06(0.82$ to 1.36$)$ & & $12.7-25.4$ & $1.04(0.80$ to 1.34$)$ & \\
\hline 3rd quintile & $20.1-27.3$ & $0.82(0.63$ to 1.06$)$ & & $25.5-48.0$ & $0.88(0.67$ to 1.14$)$ & \\
\hline 4th quintile & $27.4-37.3$ & 0.87 (0.67 to 1.13$)$ & & $48.1-102.1$ & $1.04(0.80$ to 1.35$)$ & \\
\hline 5th quintile & $37.4-272.0$ & 0.90 (0.69 to 1.17$)$ & & $\begin{array}{l}102.4- \\
22,412\end{array}$ & $1.09(0.84$ to 1.42$)$ & \\
\hline Trend & & 0.162 & & & 0.543 & \\
\hline & PFNA & & & PFHxS & & \\
\hline & $\mathrm{N}=17832$ & & & $\mathrm{~N}=17832$ & & \\
\hline $\begin{array}{l}\text { Patients without } \\
\text { diabetes }\end{array}$ & & $0.95(0.90$ to 0.99$) \dagger$ & - & & $0.96(0.93$ to 0.99$) \dagger$ & - \\
\hline Ordinal regression & & $0.97(0.93$ to 1.01$)$ & & & 0.970 .94 to 0.99 ) & \\
\hline 1st quintile & $0.25-0.9$ & Ref. & & $0.25-1.8$ & Ref. & \\
\hline 2nd quintile & $1.0-1.2$ & 0.86 (0.77 to 0.97$)$ & & $1.9-2.6$ & $0.98(0.87$ to 1.10$)$ & \\
\hline 3rd quintile & $1.3-1.5$ & $0.85(0.76$ to 0.95$)$ & & $2.7-3.7$ & $0.99(0.89$ to 1.11$)$ & \\
\hline 4th quintile & $1.6-1.9$ & $0.83(0.73$ to 0.93$)$ & & $3.8-5.7$ & $0.93(0.82$ to 1.05$)$ & \\
\hline 5th quintile & $2.0-28.6$ & 0.88 (0.78 to 0.99$)$ & & $5.8-232.6$ & 0.88 (0.79 to 0.99$)$ & \\
\hline Trend & & 0.031 & & & 0.029 & \\
\hline & $\mathrm{N}=3192$ & & & $\mathrm{~N}=3192$ & & \\
\hline $\begin{array}{l}\text { Patients with } \\
\text { diabetes }\end{array}$ & & $1.01(0.90$ to 1.13$) \dagger$ & 0.259 & 3192 & $0.99(0.92$ to 1.06$) \dagger$ & 0.683 \\
\hline Ordinal regression & & 0.99 (0.91 to 1.09$)$ & & & & \\
\hline 1st quintile & $0.25-0.8$ & Ref. & & $0.25-1.6$ & Ref. & \\
\hline 2nd quintile & $0.9-1.1$ & $1.06(0.80$ to 1.40$)$ & & $1.7-2.3$ & $1.06(0.81$ to 1.38$)$ & \\
\hline 3rd quintile & $1.2-1.4$ & $0.88(0.66$ to 1.17$)$ & & $2.4-3.2$ & 1.10 (0.85 to 1.42$)$ & \\
\hline 4th quintile & $1.5-1.8$ & 1.03 (0.77 to 1.36$)$ & & $3.3-5.0$ & $1.02(0.79$ to 1.33$)$ & \\
\hline 5th quintile & $1.9-14.5$ & $1.08(0.82$ to 1.43$)$ & & $5.1-99.7$ & $1.00(0.77$ to 1.31$)$ & \\
\hline Trend & & 0.620 & & & 0.942 & \\
\hline
\end{tabular}

(geometric) mean PFOA between districts (range 15.7405.1 ), is suggestive of a bias operating at one or both of these levels. The between-district estimate is not vulnerable to reverse causation or confounding at the individual level, though some ecological confounding may operate if it happens to correlate with the exposure level. Conversely, the within-district estimate but not between-district estimate could reflect such individual confounding if present. Thus, either the association documented at the individual level could be confounded (eg, by some unmeasured individual characteristic), or the association at the district level is confounded to obscure association (eg, socioeconomic status). This sensitivity analysis cannot prove the 
Table 4 Sensitivity analysis of the association between PFAAs and self-report memory impairment for a doubling PFAA concentration, by quintiles of PFAAs and in ordinal regression on participants aged 65 years and older $(n=7,097)$ and using any memory impairment as outcome measure $(n=21024)$

\begin{tabular}{|c|c|c|c|c|}
\hline & $\begin{array}{l}\text { Range } \\
\text { (ng/ml) }\end{array}$ & $\begin{array}{l}\text { OR }(95 \% \mathrm{Cl})^{*} \mathrm{~N}=7097 \\
\text { restricted to those } \\
\text { aged } 65+\dagger\end{array}$ & $\begin{array}{l}\text { Range } \\
\text { (ng/ml) }\end{array}$ & $\begin{array}{l}\text { OR }(95 \% \mathrm{Cl})^{\star} \mathrm{N}=21024 \\
\text { any memory impairment }\end{array}$ \\
\hline PFOS & & $0.95(0.90$ to 1.00$)$ & & $0.96(0.94$ to 0.99$)$ \\
\hline Ordinal regression & & 0.98 (0.94 to 1.03$)$ & & \\
\hline 1st quintile & $0.25-15.3$ & Ref. & $0.25-14.4$ & Ref. \\
\hline 2nd quintile & $15.4-22.0$ & 0.99 (0.83 to 1.20$)$ & $14.5-20.4$ & $0.96(0.88$ to 1.05$)$ \\
\hline 3rd quintile & $22.1-28.9$ & 0.95 (0.79 to 1.14$)$ & $20.5-27.1$ & $0.90(0.82$ to 0.98$)$ \\
\hline 4th quintile & $29.0-4.0$ & 0.97 (0.81 to 1.16$)$ & $27.2-37.2$ & 0.94 (0.86 to 1.03$)$ \\
\hline 5th quintile & $40.1-759.2$ & $0.84(0.70$ to 1.01$)$ & 37.3-759.2 & $0.93(0.85$ to 1.02$)$ \\
\hline Trend & & 0.079 & & 0.121 \\
\hline PFOA & & 0.99 (0.97 to 1.03$)$ & & 0.97 (0.96 to 0.99$)$ \\
\hline Ordinal regression & & $1.00(0.97$ to 1.03$)$ & & \\
\hline 1st quintile & $0.25-15.0$ & Ref. & $0.25-14.0$ & Ref. \\
\hline 2nd quintile & $15.1-29.6$ & 0.91 (0.75 to 1.09$)$ & $14.1-27.0$ & $0.90(0.82$ to 0.98$)$ \\
\hline 3rd quintile & $29.7-56.8$ & $0.90(0.75$ to 1.08$)$ & $27.1-53.8$ & $0.86(0.79$ to 0.94$)$ \\
\hline 4th quintile & $56.9-123.0$ & $0.84(0.70$ to 1.01$)$ & $53.9-118.1$ & 0.87 (0.79 to 0.95$)$ \\
\hline 5th quintile & $123.1-5994.8$ & 0.99 (0.83 to 1.19$)$ & $118.3-22,412$ & 0.85 (0.78 to 0.93$)$ \\
\hline Trend & & 0.680 & & $<0.001$ \\
\hline PFNA & & 0.95 (0.87 to 1.02$)$ & & 0.98 (0.95 to 1.02$)$ \\
\hline Ordinal regression & & 0.99 (0.93 to 1.07$)$ & & \\
\hline 1st quintile & $0.25-0.8$ & Ref. & $0.25-0.90$ & Ref. \\
\hline 2nd quintile & $0.9-1.1$ & 0.88 (0.73 to 1.06$)$ & $1.0-1.2$ & $0.89(0.82$ to 0.97$)$ \\
\hline 3rd quintile & $1.2-1.4$ & 0.81 (0.67 to 0.98$)$ & $1.3-1.4$ & $0.94(0.85$ to 1.04$)$ \\
\hline 4th quintile & $1.5-1.8$ & 0.82 (0.68 to 0.99$)$ & $1.5-1.9$ & $0.92(0.85$ to 1.01$)$ \\
\hline 5th quintile & $1.9-11.7$ & $0.88(0.73$ to 1.07$)$ & $2.0-28.6$ & 0.94 (0.86 to 1.03$)$ \\
\hline Trend & & 0.177 & & 0.493 \\
\hline PFHxS & & 0.96 (0.91 to 1.01$)$ & & 0.97 (0.94 to 0.99$)$ \\
\hline Ordinal regression & & 0.98 (0.93 to 1.02$)$ & & \\
\hline 1st quintile & $0.25-1.9$ & Ref. & 0.25 to 1.7 & Ref. \\
\hline 2nd quintile & $2.0-2.8$ & $0.98(0.82$ to 1.18$)$ & 1.8 to 2.6 & $0.98(0.90$ to 1.07$)$ \\
\hline 3rd quintile & 2.9-3.9 & 0.95 (0.79 to 1.15$)$ & 2.7 to 3.6 & $1.03(0.94$ to 1.13$)$ \\
\hline 4th quintile & $4.0-6.0$ & $0.98(0.82$ to 1.17$)$ & 3.7 to 5.6 & $0.96(0.87$ to 1.04$)$ \\
\hline 5th quintile & $6.1-232.6$ & 0.86 (0.71 to 1.03$)$ & 5.7 to 232.6 & 0.89 (0.81 to 0.97$)$ \\
\hline Trend & & 0.139 & & 0.010 \\
\hline \multicolumn{5}{|c|}{$\begin{array}{l}\text { *Model } 2 \text { includes age (1-year age bands), ethnicity, gender, and school level (categorical), household income (categorical), physical activity, } \\
\text { alcohol consumption (categorical, none/<1drink/month, }<1 \text { drink/week, few drinks/week, } 1-3 \text { drinks/day, }>3 \text { drinks/day, undetermined) and } \\
\text { cigarette smoking (categorical, never, former, }<10 \text { cigarette/day, } 12-20 \text { cigarette/day, } 20+\text { cigarette/day). } \\
\text { †Sensitivity analysis including participants aged } 65 \text { years or older only }(\mathrm{N}=7097) \text {. } \\
\text { †Sensitivity analysis using a more restrictive definition of memory impairment (those reporting frequent episode of short-term memory loss } \\
\text { only, cases=1115). } \\
\text { PFAA, perfluoroalkyl acids; PFHxS, perfluorohexane sulfonate; PFNA, perfluorononanoic acid; PFOA, perfluorooctanate; PFOS, } \\
\text { perfuorooctane sulfonate. }\end{array}$} \\
\hline
\end{tabular}

presence of confounding at either level, but if the association had been consistent at both the individual and district levels, that would have been more convincing evidence of the association being due to PFAAs.

The size of the associations observed has both strong and weak aspects. The strong statistical significance suggests that chance is an unlikely explanation. However, the ORs are only modestly different from one, 0.75 at the most extreme, so that biases are a more plausible explanation than they would be with more extreme ratios. In conclusion, these data show an inverse association between PFOA and PFOS exposure and selfreported memory impairment, particularly in patients without diabetes. This can be potentially explained by the preventive anti-inflammatory effect exerted by a PPAR agonist effect of these PFAAs, but confounding or even reverse causation cannot be excluded as an alternative explanation.

Acknowledgements We are grateful to Dr Marc Weisskopf for his thoughtful comments on the draft of this manuscript, and for constructive idea sharing and discussions on this topic.

Contributors VG had full access to all of the data in the study and takes responsibility for the integrity of the data and accuracy of the data analysis. TF, BA and VG participated in the study concept and design. VG, TF and BA participated in the analysis and interpretation of data. VG participated in the drafting of the manuscript. TF participated in data collection. CB and GL 
participated in a critical revision of the manuscript for important intellectual content. All authors have read and approved the final manuscript.

Funding C8 Class Action Settlement Agreement (Circuit Court of Wood County, West Virginia, USA) between DuPont and the plaintiffs, which resulted from releases of perfluorooctanoate (PFOA, or C8) into drinking water.

Competing interests None.

Ethics approval The LSHTM Ethics Committee approved this study.

Provenance and peer review Not commissioned; externally peer reviewed.

Data sharing statement No extra data are available.

\section{REFERENCES}

1. Kato K, Wong LY, Jia LT, et al. Trends in exposure to polyfluoroalkyl chemicals in the U.S. population: 1999-2008 (dagger). Environ Sci Technol 2011:45:8037-45.

2. Tao L, Kannan K, Kajiwara N, et al. Perfluorooctanesulfonate and related fluorochemicals in albatrosses, elephant seals, penguins, and polar skuas from the Southern Ocean. Environ Sci Technol 2006;40:7642-8.

3. Kim SK, Lee KT, Kang CS, et al. Distribution of perfluorochemicals between sera and milk from the same mothers and implications for prenatal and postnatal exposures. Environ Pollut 2011;159:169-74.

4. Lau C, Anitole K, Hodes C, et al. Perfluoroalkyl acids: a review of monitoring and toxicological findings. Toxicol Sci 2007;99:366-94.

5. D'Hollander W, de Voogt $P$, De Coen W, et al. Perfluorinated substances in human food and other sources of human exposure. Rev Environ Contam Toxicol 2010;208:179-215.

6. Goosey E, Harrad S. Perfluoroalkyl compounds in dust from Asian, Australian, European, and North American homes and UK cars, classrooms, and offices. Environ Int 2011;37:86-92.

7. DeWitt JC, Shnyra A, Badr MZ, et al. Immunotoxicity of perfluorooctanoic acid and perfluorooctane sulfonate and the role of peroxisome proliferator-activated receptor alpha. Crit Rev Toxicol 2009;39:76-94.

8. Peters JM, Gonzalez FJ. Why toxic equivalency factors are not suitable for perfluoroalkyl chemicals. Chem Res Toxicol 2011;24:1601-9.

9. Howroyd P, Swanson C, Dunn C, et al. Decreased longevity and enhancement of age-dependent lesions in mice lacking the nuclear receptor peroxisome proliferator-activated receptor alpha (PPARalpha). Toxicol Pathol 2004;32:591-9.

10. Capri M, Salvioli S, Sevini F, et al. The genetics of human longevity. Ann N Y Acad Sci 2006;1067:252-63.

11. Paolisso G, Barbieri M, Rizzo MR, et al. Low insulin resistance and preserved beta-cell function contribute to human longevity but are not associated with TH-INS genes. Exp Gerontol 2001;37:149-56.

12. Heneka MT, Feinstein DL, Galea E, et al. Peroxisome proliferator-activated receptor gamma agonists protect cerebellar granule cells from cytokine-induced apoptotic cell death by inhibition of inducible nitric oxide synthase. J Neuroimmunol 1999;100:156-68.

13. Heneka MT, Klockgether T, Feinstein DL. Peroxisome proliferator-activated receptor-gamma ligands reduce neuronal inducible nitric oxide synthase expression and cell death in vivo. J Neurosci 2000;20:6862-7.

14. Combs CK, Johnson DE, Karlo JC, et al. Inflammatory mechanisms in Alzheimer's disease: inhibition of beta-amyloid-stimulated proinflammatory responses and neurotoxicity by PPARgamma agonists. J Neurosci 2000;20:558-67.

15. Kim EJ, Kwon KJ, Park JY, et al. Effects of peroxisome proliferator-activated receptor agonists on LPS-induced neuronal death in mixed cortical neurons: associated with iNOS and COX-2. Brain Res 2002;941:1-10.

16. Luna-Medina R, Cortes-Canteli M, Alonso M, et al. Regulation of inflammatory response in neural cells in vitro by thiadiazolidinones derivatives through peroxisome proliferator-activated receptor gamma activation. J Biol Chem 2005;280:21453-62.

17. Whitehead JP. Diabetes: new conductors for the peroxisome proliferator-activated receptor gamma (PPARgamma) orchestra. Int J Biochem Cell Biol 2011;43:1071-4.

18. Takacs ML, Abbott BD. Activation of mouse and human peroxisome proliferator-activated receptors (alpha, beta/delta, gamma) by perfluorooctanoic acid and perfluorooctane sulfonate. Toxicol Sci 2007;95:108-17.
19. Power MC, Webster TF, Baccarelli AA, et al. Cross-sectional association between polyfluoroalkyl chemicals and cognitive limitation in the national health and nutrition examination survey. Neuroepidemiology 2012:40:125-32.

20. McCrimmon RJ, Ryan CM, Frier BM. Diabetes and cognitive dysfunction. Lancet 2012;379:2291-9.

21. MacNeil J, Steenland NK, Shankar A, et al. A cross-sectiona analysis of type II diabetes in a community with exposure to perfluorooctanoic acid (PFOA). Environ Res 2009;109:997-1003.

22. Steenland K, Fletcher T, Savitz DA. Epidemiologic evidence on the health effects of perfluorooctanoic acid (PFOA). Environ Health Perspect 2010;118:1100-8.

23. Lin CY, Chen PC, Lin YC, et al. Association among serum perfluoroalkyl chemicals, glucose homeostasis, and metabolic syndrome in adolescents and adults. Diabetes Care 2009;32:702-7.

24. Lundin Jl, Alexander BH, Olsen GW, et al. Ammonium perfluorooctanoate production and occupational mortality. Epidemiology 2009;20:921-8.

25. Frisbee SJ, Brooks AP Jr, Maher A, et al. The C8 health project: design, methods, and participants. Environ Health Perspect 2009;117:1873-82.

26. Steenland K, Jin C, MacNeil J, et al. Predictors of PFOA levels in community surrounding a chemical plant. Environ Health Perspect 2009;117:1083-8

27. Kuklenyik Z, Reich JA, Tully JS, et al. Automated solid-phase extraction and measurement of perfluorinated organic acids and amides in human serum and milk. Environ Sci Technol 2004;38:3698-704.

28. Gallo V, Egger M, McCormack V, et al. STrengthening the Reporting of OBservational studies in Epidemiology-Molecular Epidemiology (STROBE-ME): an extension of the STROBE statement. PLoS Med 2011;8:e1001117

29. Gallo V, Leonardi G, Genser B, et al. Serum perfluorooctanoate (PFOA) and perfluorooctane sulfonate (PFOS) concentrations and liver function biomarkers in a population with elevated PFOA exposure. Environ Health Perspect 2012;120:655-60.

30. Lleo A, Galea E, Sastre M. Molecular targets of non-steroidal anti-inflammatory drugs in neurodegenerative diseases. Cell Mol Life Sci 2007:64:1403-18

31. Alafuzoff I, Overmyer M, Helisalmi S, et al. Lower counts of Astroglia and activated Microglia in patients with Alzheimer's disease with regular use of non-steroidal anti-inflammatory drugs. J Alzheimer's Dis 2000;2:37-46.

32. Jimenez S, Baglietto-Vargas D, Caballero C, et al. Inflammatory response in the hippocampus of PS1M146L/APP751SL mouse model of Alzheimer's disease: age-dependent switch in the microglial phenotype from alternative to classic. J Neurosci 2008;28:11650-61.

33. Revill P, Moral MA, Prous JR. Impaired insulin signaling and the pathogenesis of Alzheimer's disease. Drugs Today (Barc) 2006;42:785-90.

34. Anbalagan M, Huderson B, Murphy L, et al. Post-translational modifications of nuclear receptors and human disease. Nucl Recept Signal 2012;10:e001.

35. Choi JH, Banks AS, Estall JL, et al. Anti-diabetic drugs inhibit obesity-linked phosphorylation of PPARgamma by Cdk5. Nature 2010;466:451-6.

36. Hauser S, Adelmant G, Sarraf P, et al. Degradation of the peroxisome proliferator-activated receptor gamma is linked to ligand-dependent activation. J Biol Chem 2000;275:18527-33.

37. Wolf CJ, Takacs ML, Schmid JE, et al. Activation of mouse and human peroxisome proliferator-activated receptor alpha by perfluoroalkyl acids of different functional groups and chain lengths. Toxicol Sci 2008:106:162-71.

38. Johansson N, Eriksson P, Viberg H. Neonatal exposure to PFOS and PFOA in mice results in changes in proteins which are important for neuronal growth and synaptogenesis in the developing brain. Toxicol Sci 2009; 108:412-18.

39. Johansson N, Fredriksson A, Eriksson P. Neonatal exposure to perfluorooctane sulfonate (PFOS) and perfluorooctanoic acid (PFOA) causes neurobehavioural defects in adult mice. Neurotoxicology 2008;29:160-9.

40. Viberg H, Lee I, Eriksson P. Adult dose-dependent behavioral and cognitive disturbances after a single neonatal PFHxS dose. Toxicology 2013;304:185-91.

41. Staels B, Fruchart JC. Therapeutic roles of peroxisome proliferator-activated receptor agonists. Diabetes 2005;54:2460-70.

42. Ferri CP, Prince M, Brayne C, et al. Alzheimer's Disease International. Global prevalence of dementia: a Delphi consensus study. Lancet 2005;366:2112-7. 